\title{
EFFECT OF CLIMATE CHANGE ON ORIENTAL FRUIT FLY IN NEW ZEALAND AND THE PACIFIC
}

\author{
D.J. KRITICOS ${ }^{1,2}$, A.E.A. STEPHENS ${ }^{3}$ and A. LERICHE ${ }^{1,2}$ \\ ${ }^{1}$ Ensis, Private Bag 3020, Rotorua, New Zealand \\ ${ }^{2}$ Current address: Ensis, PO Box E4008, Kingston ACT 2604, Australia \\ ${ }^{3}$ HortResearch, PO Box 51, Lincoln, New Zealand
}

Corresponding author: Darren.Kriticos@ensisjv.com

\begin{abstract}
A CLIMEX ${ }^{\mathrm{TM}}$ model of the Oriental fruit fly (OFF) indicates that under the reference climate (1961-1990), OFF could persist throughout most of the central Pacific. In New Zealand, it could establish throughout much of the low-lying areas of the North Island, and much of New Zealand could support short-term populations during the summer months. Climate change scenarios for the 2080s indicate that in the central Pacific, the change in potential distribution is relatively minor. However, parts of New Zealand could become substantially more climatically suitable, increasing the likelihood of successful establishment of OFF after an incursion, and seriously threatening the horticultural sector. Should OFF become established in New Zealand, it is likely to follow any expansion of the horticultural sector into the coastal areas of the eastern part of the South Island as far south as Oamaru.
\end{abstract}

Keywords: CLIMEX, climate change, invasive species, Bactrocera dorsalis, Tephritidae.

\section{INTRODUCTION}

Bactrocera dorsalis (Hendel) (Diptera: Tephritidae), the oriental fruit fly (OFF), is a major pest of a wide variety of unrelated fruit crops throughout South East Asia to India (EPPO 1997; Waterhouse 1993). Additionally, OFF has become established in a number of other countries, and is a very damaging pest wherever it occurs (PMP-FFM, 2004). It has been successfully eradicated from a number of countries, including the Ryukyu Islands in Japan and Nauru, Guam and the Northern Mariana Islands in the Pacific. It is currently the subject of an eradication plan in French Polynesia (PMP-FFM, 2004). Four infestations of OFF were eradicated from California between 1960 and 1997 (Weems et al. 2004). It has been intercepted without establishing at a number of ports throughout the world and has been described as a chronically invading species (Mangan \& Moreno 2002).

As a result of its widespread distribution, pest status, invasive ability and potential impact on market access, OFF and many other fruit fly species are considered major threats to New Zealand and, as such, have been declared "Notifiable Organisms" by Biosecurity New Zealand (MAF 2004). A permanent trapping regime is in place throughout the country in order to detect any incursion (Stephenson et al. 2003). Market access restrictions were applied by New Zealand's trading partners immediately following the discovery of an incursion by Mediterranean fruit fly, Ceratitis capitata (Wiedemann), in 1996 (SriRamaratnam 1996). Despite the species being eradicated within 1 month of the initial detection, the response to Mediterranean fruit fly suggests that even if OFF was eradicated quickly, an incursion could have major economic impacts. OFF is also a major threat to the tropical Pacific Islands. It has established in a number of islands throughout the Pacific and has been eradicated from some. As trade and tourism in the Pacific region increases, the potential for additional incursions increases. In the Pacific Islands, there 
is a range of other species of Bactrocera, and the potential distribution of OFF may be limited by competitive interaction with other species. A quarantine surveillance system focusing on fruit flies has been established in the Pacific Islands (Allwood 2000).

Stephens et al. (2007) developed a CLIMEX model for Oriental fruit fly and considered the impact of global climate change on its potential distribution. In this paper, the potential for establishment of OFF in New Zealand and the central Pacific under the current reference climate and future climate change scenarios is examined in detail. This information should help inform the region's biosecurity agencies of the risk posed by OFF.

\section{Climate data}

\section{METHODS}

The climate data used in this project were from the University of East Anglia Climate Research Unit TYN SC 2.0 dataset (Mitchell et al. 2004). The TYN SC 2.0 dataset is a gridded global terrestrial climatology at 0.5 arc degree resolution (approximately 50 $\mathrm{km}$ between each data point). The dataset includes the following climate variables: average monthly precipitation, temperature, daily temperature range and vapour pressure. Using these variables, estimates were made for monthly averages of daily maximum temperature, daily minimum temperature and relative humidity at 0900 and 1500 hours (Stephens et al. 2007).

The TYN SC 2.0 dataset includes data for the reference climate (1961-1990) and also climate change scenario results from five global climate models, although only the CSIRO Mark2 model (Hirst et al. 2000) was used here because it provided good median results for the South Pacific region compared with other models (Ruosteenoja et al. 2003). The change surfaces in the TYN SC 2.0 dataset were taken from global climate models run with the four emissions scenarios described in the Special Report on Emission Scenarios (IPCC 2000). These emission scenarios specify equally plausible future states of socio-economic and technological development. Two extreme scenarios (B1 and A2, Table 1) were selected to represent the range of ecological scenarios for OFF. These data and the processing needed to format them for CLIMEX are described in detail in Stephens et al. (2007).

TABLE 1: Special Report on Emission Scenarios (SRES) markers and calculated variables. Scenarios have been ordered in terms of their potential for impact. Source: Carter et al. (1999).

\begin{tabular}{lcccc}
\hline & \multicolumn{5}{c}{ SRES marker scenarios for 2100} \\
\hline Scenario & $\mathrm{B} 1$ & $\mathrm{~B} 2$ & $\mathrm{~A} 1$ & $\mathrm{~A} 2$ \\
Human Population (billion) & 7.2 & 10.4 & 7.1 & 15.1 \\
Atmospheric $\mathrm{CO}_{2}$ concentration (ppmv) & 547 & 601 & 680 & 834 \\
Global annual-mean temperature change $\left({ }^{\circ} \mathrm{C}\right)$ & 2.04 & 2.16 & 2.52 & 3.09 \\
\hline
\end{tabular}

\section{CLIMEX model}

The CLIMEX model for OFF was fitted to the known geographic range using the procedure described in the users guide (Sutherst et al. 2007) under the reference climate. Using this method, the model parameters (Table 2) were manually iteratively adjusted until the simulated geographical distribution indicated by the Ecoclimatic Index (EI) values agreed with the species known native distribution. Full details of the model can be found in Stephens et al. (2007).

The reference climate dataset was used in CLIMEX to project the threat posed by OFF under current climate conditions. Despite the slight rise in global temperatures since 1990 , this should still provide the best indication of the current risk. The future risk was gauged using climate projections for the 30 year average centred on 2085 . 
TABLE 2: Parameters used in the CLIMEX model for Oriental fruit fly (Bactrocera dorsalis).

\begin{tabular}{lcc}
\hline Parameter & Mnemonic & Value $^{1}$ \\
\hline Limiting low temperature & DVO & $13^{\circ} \mathrm{C}$ \\
Lower optimal temperature & DV1 & $25^{\circ} \mathrm{C}$ \\
Upper optimal temperature & DV2 & $33^{\circ} \mathrm{C}$ \\
Limiting high temperature & DV3 & $36^{\circ} \mathrm{C}$ \\
Limiting low soil moisture & SM0 & 0.1 \\
Lower optimal soil moisture & SM1 & 0.25 \\
Upper optimal soil moisture & SM2 & 1 \\
Limiting high soil moisture & SM3 & 1.5 \\
Cold stress temperature threshold & TTCS & $2.5^{\circ} \mathrm{C}$ \\
Cold stress temperature rate & THCS & -0.012 week $^{-1}$ \\
Minimum degree day cold stress threshold & DTCS & $8^{\circ} \mathrm{C} \mathrm{days}^{-1}$ \\
Degree-day cold stress rate & DHCS & -0.002 week $^{-1}$ \\
Heat stress temperature threshold & TTHS & $36^{\circ} \mathrm{C}$ \\
Heat stress temperature rate & THHS & 0.005 week $^{-1}$ \\
Dry stress threshold & SMDS & 0.1 \\
Dry stress rate & HDS & -0.024 week $^{-1}$ \\
Wet stress threshold & SMWS & 1.5 \\
Wet stress rate & HWS & 0.007 week $^{-1}$ \\
Degree days per generation & PDD & $470^{\circ} \mathrm{C} \mathrm{days}$ \\
\hline
\end{tabular}

${ }^{1}$ Values without units are dimensionless indices.

\section{RESULTS}

Under current climate OFF is projected to be capable of establishing persistent populations in much of the low-lying areas of New Zealand's North Island (Fig. 1a). There is potential for establishment of permanent populations throughout Northland, Auckland, the Coromandel Peninsula, northern Waikato and in coastal areas south to Cape Turnagain and Foxton. Current climatic conditions are projected to be unsuitable for OFF establishment in the South Island.

Under the future climate scenarios (Figs $1 \mathrm{~b} \&$ 1c), the area of New Zealand projected to be climatically suitable for OFF increased to cover all of the lowland regions in the North Island and the warmer parts of the South Island. Under the milder B1 scenario (Fig. $1 \mathrm{~b}$ ), areas along the east coast of the South Island to the Rangitata River are projected to be marginally suitable for OFF, while under the more extreme A2 scenario (Fig. 1c), climatically marginal habitat is projected to extend further south to Oamaru. Additionally, the suitability of regions that are projected to be presently suitable increased under the A2 scenario. Under this scenario the areas around Auckland and Hawke's Bay are projected to be climatically optimal regions for OFF. On the western part of the South Island conditions generally remain unsuitable due to excessive cold stress in elevated areas and wet stress in lowland areas. Small isolated patches on the west coast of the South Island may become marginally suitable under the A2 scenario. 

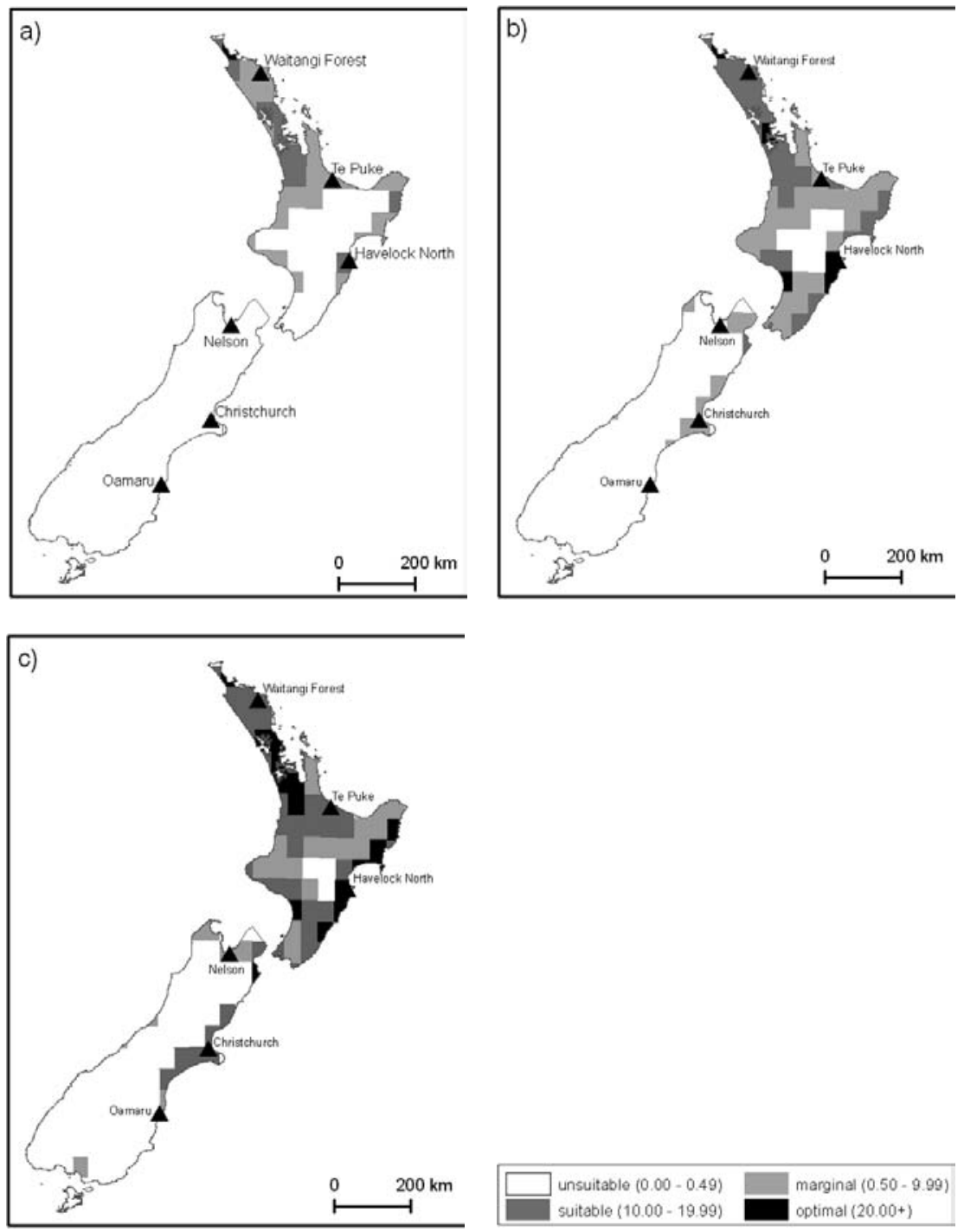

FIGURE 1: Distribution of Oriental fruit fly in New Zealand under (a) current climate (1961-1990 average), (b) CSIRO Mark2 global climate model under the IPCC B1 climate change scenario for the 2080s and (c) the CSIRO Mark2 global climate model under the IPCC A2 climate change scenario for the 2080s. 
OFF is projected to be able to survive throughout the Pacific under current climate conditions (Fig. 2a). The high projected EI values and the previous incursion history, suggests that OFF has the potential to become a major pest were it to establish on most of the Pacific Islands with optimal conditions in Kiribati, New Caledonia, Tonga and much of French Polynesia.

Projected optimal distribution for OFF in the Pacific under climate change scenarios (Fig. 2b \& 2c) does not substantially differ from the projected optimal distribution under current climatic conditions. Most of the Pacific Islands are already considered optimal habitat for OFF. One notable change is that Kiribati decreases in suitability under the A2 scenario due to increasing wet stress.

\section{DISCUSSION}

OFF is projected to be able to establish in much of New Zealand's North Island in northern and central coastal regions. An incursion of OFF could have a major impact on the citrus and avocado industries in particular. Several species of citrus (Citrus limon, Citrus maxima, Citrus reticulata and Citrus sinensis) are considered primary hosts of OFF (CABI 2004), and avocado is also commonly attacked (Weems et al. 2004). In 2004/2005 New Zealand had 680 ha of mandarins and 3400 ha of avocados under cultivation (Statistics New Zealand 2005), almost all of which are in areas projected to be suitable for OFF under current climate conditions. Even if OFF did not reach pest status in New Zealand, the impact on market access would be potentially severe. While South Island and inland and southern North Island are presently unlikely to support a long-term population, the CLIMEX Growth Index (data not shown) indicates that most parts of New Zealand may be able to support OFF populations in the short term during the warmer months. Following an incursion, OFF could spread into areas where it could survive a season, and would almost certainly lead to additional market access trade restrictions being placed on New Zealand produce. Under the current climate regime, many regions of New Zealand, such as Nelson and Wellington, may support transient OFF populations for a number of years if winters are mild.

The increasing threat from OFF to New Zealand due to climate change is significant in national terms. Even under the conservative B1 scenario, the likely potential range of OFF in New Zealand is likely to expand southward, with some areas likely to have an optimal climate in the 2080s. This threat is heightened by the increasing climate suitability of both the Pacific Islands and the eastern seaboard of Australia, which could act as stepping-stones for an invasion of New Zealand.

The CLIMEX analysis is at least partly validated by the presence of OFF or ecologically similar congeners of OFF on various Pacific Islands. An OFF incursion could lead to market access restrictions being imposed until protocols for fruit disinfestation were determined, and it is likely that non-host status of some fruit would be permanently revoked. Currently, the islands use non-host status (a claim that suitable host plants are not found within the jurisdiction) and/or heat treatment to eradicate fruit flies from export fruit (PMP-FFM 2004). In the Pacific region, OFF has been found in Hawaii, Nauru (since eradicated) and French Polynesia (currently under an eradication plan). In all of these countries, OFF has been deemed a serious pest (PMP-FFM, 2004). These experiences (and high projected climate suitability) suggest that OFF has the potential to become a serious pest on other islands in the Pacific as well. The projected impact of climate change on the climatic suitability of the Pacific for OFF is minimal, with the greatest change being a reduced climatic suitability of Kiribati under the more severe A2 scenario. Thus, the majority of the Pacific islands will continue to pose a steppingstone invasion threat for OFF and similar fruit flies to New Zealand and Australia. 

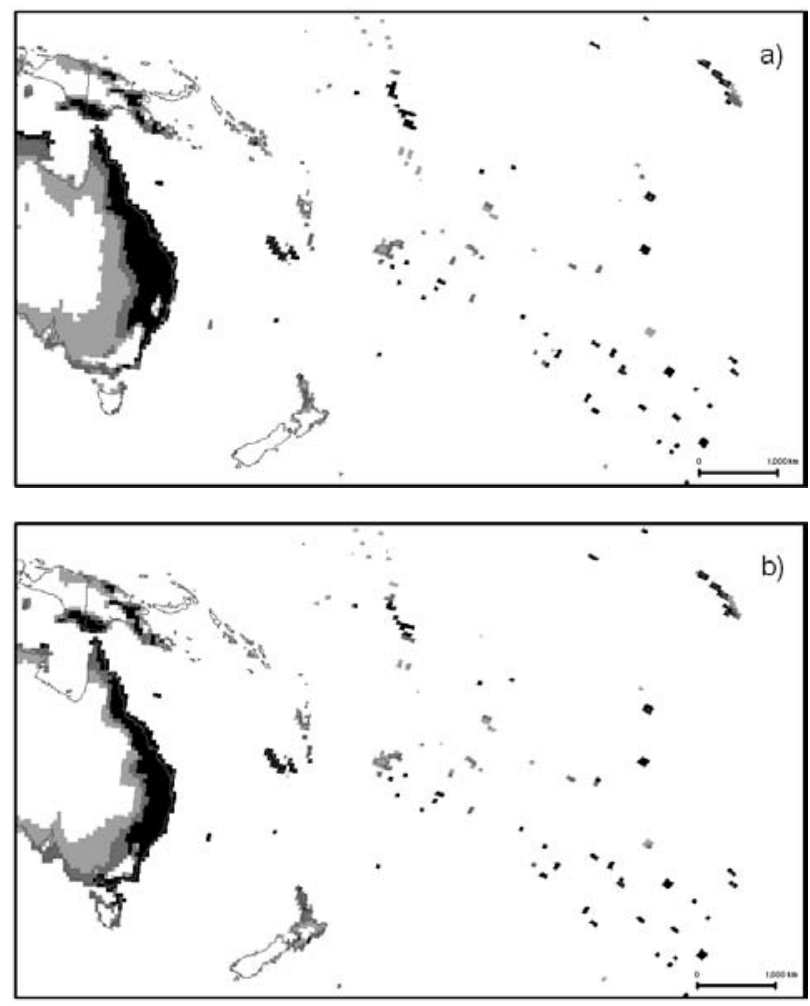

unsuitable $(0.00-0.49)$ suitable $(10.00-19.99)$ marginal $(0.50-9.99)$ optimal $(20.00+)$

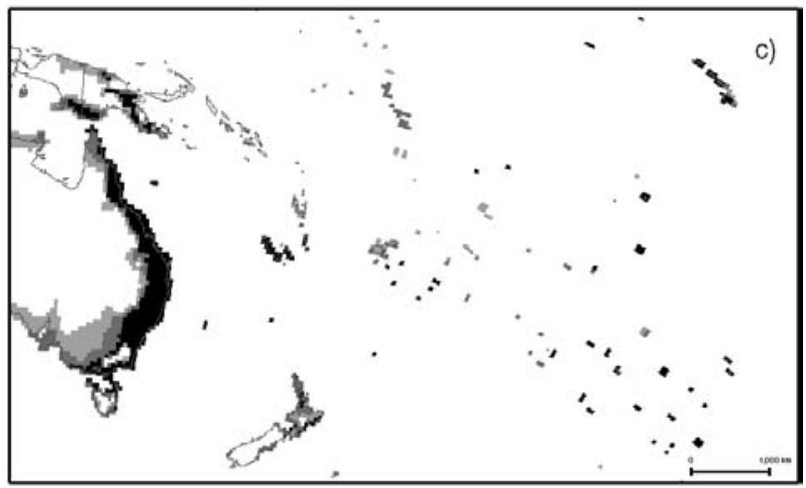

FIGURE 2: Distribution of Oriental fruit fly in the Pacific under (a) current climate (1961-1990 average), (b) CSIRO Mark2 global climate model under the IPCC B1 climate change scenario for the 2080s and (c) the CSIRO Mark2 global climate model under the IPCC A2 climate change scenario for the 2080s. 


\section{ACKNOWLEDGEMENTS}

This work was funded by New Zealand's Foundation for Research, Science and Technology through contract CO2X0501, the Better Border Biosecurity (B3) Programme (www.b3nz.org). We thank Dr Barbara Barratt and Mr Nod Kay for providing useful comments on the manuscript.

\section{REFERENCES}

Allwood A 2000. Regional approach to the management of fruit flies in the Pacific. Joint Proceedings of the International Conference on area-wide control of Insect Pests and the Fifth International Symposium on Fruit flies of Economic Importance. Penang, Malaysia. 28 May - 2 June 1998. Pp. 439-448.

CABI 2004. Crop Protection Compendium. http://www.cabicompendium.org (last accessed 19 May 2007).

Carter TR, Hulme M, Lal M 1999. Guidelines on the Use of Scenario Data for Climate Impact and Adaptation Assessment. Intergovernmental Panel on Climate Change. http://www.ipcc-data.org/guidelines/ggm_no1_v1_12-1999.pdf (last accessed 19 May 2007). 69 pp.

EPPO 1997. Bactrocera dorsalis. In: Smith IM, McNamara DG, Scott PR, Holderness $\mathrm{M}$ ed. EPPO/CABI Quarantine Pests for Europe. 2nd edition. CABI International, Wallingford, UK.

Hirst AC, O'Farrell SP, Gordon HB 2000. Comparison of a coupled ocean-atmosphere model with and without oceanic eddy-induced advection. 1. Ocean spin-up and control integrations. Journal of Climate 13: 139-163.

IPCC 2000. Special Report on Emissions Scenarios: A Special Report of Working Group III of the Intergovernmental Panel on Climate Change. Cambridge University Press, Cambridge, UK. 570 pp.

MAF 2004. The Unwanted Organisms Register. http://www.maf.govt.nz/biosecurity/ pests-diseases/registers-lists/unwanted-organisms/ (last accessed 20 June 2006).

Mangan RL, Moreno DS 2002. Application of insect behavior and population ecology to reduce risk of introduction and establishment of exotic fruit flies. In: Hallman GJ, Schwalbe CP ed. Invasive arthropods in agriculture: problems and solutions. Science Publishers Inc, Enfield, NH, USA. Pp. 207-242.

Mitchell TD, Carter TR, Jones PD, Hulme M, New M 2004. A comprehensive set of climate scenarios for Europe and the globe: the observed record (1900-2000) and 16 scenarios (2000-2100). University of East Anglia, Working Paper 55. http://www. tyndall.ac.uk/publications/working_papers/wp55_summary.shtml (last accessed 19 May 2007). 30 pp.

PMP-FFM (Pest management in the Pacific project) 2004. Pacific fruit fly web. http:// www.spc.int/pacifly/ (last accessed 20 June 2006).

Ruosteenoja K, Carter TR, Jylhä K, Tuomenvirta H 2003. Future climate in world regions: an intercomparison of model-based projections for the new IPCC emissions scenarios. The Finnish Environment 644, Finnish Environment Institute, Helsinki, Finland. 83 pp.

SriRamaratnam R 1996. Fruit fly: a major threat to New Zealand's fruit and vegetable industries? http://www.maf.govt.nz/mafnet/rural-nz/research-and-development/ pest-control/fruitfly-threat/httoc.htm (last accessed 20 June 2006).

Statistics New Zealand 2005. Agricultural Production Statistics (Provisional) June 2005. Statistics New Zealand, http://www.stats.govt.nz/store/2006/07/agriculturalproduction-statistics-provisional-jun05-hotp.htm?page=para012Master (last accessed 19 May 2007).

Stephens AEA, Kriticos DJ, Leriche A 2007. The current and future potential geographic distribution of the Oriental fruit fly, Bactrocera dorsalis, (Diptera: Tephritidae). Bulletin of Entomological Research 97: doi:10.1017/S0007485307005044. 
Stephenson BP, Gill GSC, Randall JL, Wilson JA 2003. Biosecurity approaches to surveillance and response for new plant pest species. New Zealand Plant Protection 56: 5-9.

Sutherst RW, Maywald GF, Kriticos DJ 2007. CLIMEX Version 3: User's Guide. www. Hearne.com.au (last accessed 19 May 2007). Hearne Scientific Software Pty Ltd. $131 \mathrm{pp}$.

Waterhouse DF 1993. The major arthropod pests and weeds of agriculture in Southeast Asia. Aciar Monograph No. 21.

Weems HV, Heppner JB, Nation JL, Fasulo TR 2004. Oriental fruit fly, Bactrocera (=Dacus) dorsalis (Hendel) (Insecta: Diptera: Tephritidae). University of Florida Featured Creatures. http://creatures.ifas.ufl.edu/fruit/tropical/oriental_fruit_fly.htm (last accessed 20 June 2006). 